\title{
Occupational Training for Women with Parkinson's Disease: An Experience of Cooking Activities
}

\author{
Sara Piccoli, Silvia Pizzighello*, Chiara Gava, Andrea Martinuzzi \\ Unit for the Rehabilitation of Neuropsychological Disorders, “E. Medea” Scientific Institute, Pieve di Soligo, Italy \\ Email: *silvia.pizzighello@ps.lnf.it
}

How to cite this paper: Piccoli, S., Pizzighello, S., Gava, C., \& Martinuzzi, A. (2018). Occupational Training for Women with Parkinson's Disease: An Experience of Cooking Activities. Psychology, 9, 977-984. https://doi.org/10.4236/psych.2018.95061

Received: March 14, 2018

Accepted: May 11, 2018

Published: May 17, 2018

Copyright $\odot 2018$ by authors and Scientific Research Publishing Inc. This work is licensed under the Creative Commons Attribution International License (CC BY 4.0).

http://creativecommons.org/licenses/by/4.0/

\begin{abstract}
Parkinson's Disease is a progressive disorder of the nervous system which frequently starts before the sixth decade of life. This is a preliminary overview concerning the effect of a training on cooking with four women with Parkinson's Disease. Cooking is a complex activity that requires functions as attention, memory and task organization; fine motor skills and bimanual coordination are also involved. Moreover, this kind of activity is important for women to maintain their social role as housewives. The assessment was done before and after the training and included: The Unified Parkinson's Disease Rating Scale (UPDRS), Parkinson's Disease Quality of Life questionnaire (PDQL), Schwab \& England Scale, Functional Independence Measure (FIM) and a cooking test. The training consisted of 10 group sessions of 90 minutes each one. At the end of the cooking training, the level of disability, measured by the UPDRS, decreased for all participants as well as the time required to perform a cooking test. Scores on other test were unvaried. A cooking training may be useful to improve the course of the Parkinson's disease and should be included in a comprehensive rehabilitation program.
\end{abstract}

\section{Keywords}

Parkinson's Disease, Functional Therapy, Rehabilitation

\section{Introduction}

Parkinson disease is one of the most frequent diseases of the central nervous system (Cholewa et al., 2014). It usually begins before the sixth decade of life (Pezzoli \& Tesei, 2015), however, approximately $10 \%$ of the people affected are less than 45 years old. 
This progressive neurodegenerative disorder is characterized by resting tremor, bradykinesia, rigidity and postural instability (Cholewa et al., 2014). As the disease progresses, it leads to increasing limitation of the motor, cognitive and functional abilities that are fundamental for any activity related to daily life. Body and structure impairments, participation restriction and limitations on activities, as defined by the International Classification of Functioning, Disability and Health (ICF) impact the execution of tasks or actions, lead to disability (World Health Organization, 2001).

In the most advanced stages (Macleod et al., 2016), there may be a complete loss of independence therefore the burden of management falls on the family. This issue obviously compromises both the patient and his/her family's quality of life. Pharmacological support aims to reduce the symptoms and slow down the progression of the disease. Rehabilitation may also help to slow the disease as well as to limit disability, supporting independence. This support helps patients achieve a better quality of life, which is defined as the subjective perception that each person has of his/her own position in life, into his/her culture, and into his/her jobs, in relation to his/her objectives, expectations and worries (World Health Organization, 1948).

The aim of the therapy with patients with Parkinson's disease is to maintain the best degree of independence. Occupational training concerning daily living activities are a relevant tool to support the independent living and quality of life in clients with Parkinson's disease. Here is a description of the preliminary results of training on the activity of cooking with four women with Parkinson's disease.

Hartmann (2000) suggested that women with Parkinson's disease usually prepare frugal meals due to their slowness of movement, rigidity and tremor. Frequently this problem leads to them allowing their caregiver to cook, thereby, losing an important and satisfying activity of their daily lives. We hypothesized that a training in cooking may stimulate the participation in activities of daily living (ADL), that individuals normally do to take care of themselves, in women with Parkinson's disease and may strengthen their role as housewife.

\section{Materials and Methods}

\subsection{Participants}

Patients with Parkinson's disease admitted to the training were females, less than 75 years old with no currently other neurological or psychiatric disease. Inclusion criteria were: a score $<3$ on the Hoehn and Yahr Scale (Hoehn \& Yahr, 1967), score $\geq 85$ at the Functional Independence Measure (FIM) (UDSmr, Buffalo-NY, USA Center for Functional Assessment Research, 2006) and a score $\geq$ 24 at the Mini Mental State Examination (Tombaugh \& McIntyre, 1992). Two patients were treated surgically with Deep Brain Stimulation (6 and 9 months before, respectively), one patient suffered from depression that was treated with antidepressants. They were all housewives but their role in the management of 
cooking activities decreased subsequent to the progression of the disease, especially due to the extreme slowness during movements.

The training occurred in the occupational unit of "E. Medea" Center for the Rehabilitation of Neuropsychological Disorders of Pieve di Soligo. During the training all patients received other treatments, mainly motor. The type of treatments and their frequency was determined by their personalized rehabilitation program that was decided by the physician together with the team of professionals on the basis of needs. The project was approved by the Institutional Review Board "E. Medea" Center for the Rehabilitation of Neuropsychological Disorders of Pieve di Soligo and all participants provided informed consent.

\subsection{Materials}

At the beginning and at the end of training, patients were assessed using: the Unified Parkinson's Disease Rating Scale (Fahn \& Elton, 1987), the Parkinson's Disease Quality of Life questionnaire (Hobson et al., 1999), the Schwab \& England Scale (Schwab et England, 1969), the Functional Independence Measure (FIM) (UDSmr, Buffalo-NY, USA Center for Functional Assessment Research, 2006) and a cooking test.

The Unified Parkinson's Disease Rating Scale allows to follow the course of Parkinson's disease. It is made up of the Mentation, Behavior, and Mood, ADL and Motor sections. The maximum score is of 199 points. 199 represents the worst (total) disability whereas 0 represents no disability. The Parkinson's Disease Quality of Life questionnaire allows to investigate the level of difficulty the client finds in daily life during the last three months. They have to think about their general well-being and to consider how often in the three months they have experienced specific events (for example, difficulty walking). We asked them to indicate the frequency of each event by selecting one of 5 options (never/occasionally/sometimes/often/always).

The $S c h w a b$ \& England Scale rates the impairment on daily functions. The maximum score is $100 \%$ and represents complete independence, whereas $0 \%$ represents a total dependent state. The FIM measures the amount of disability and the need for physical and cognitive assistance to perform activities of daily living. Total FIM scores range from 18 (totally dependent) to 126 (totally independent). The cooking test was performed to observe the efficacy and speed of daily living activities (e.g., preparation of an instant pizza). In order to assess how well they perform the activity, the task was divided into separate steps (for example: take a tablespoon, add water to the dough, put the dough in the oven) and each one was considered in terms of physical effort and/or efficiency, safety, and need for assistance.

In addition to tests, a final questionnaire for satisfaction was administered. It consists of 17 "Yes/No" questions concerning the following aspects: satisfaction about the training (usefulness, difficulties), satisfaction about the therapist (expertise, helpfulness), relationship with other participants, perceived self-efficacy 
and state of moods.

\subsection{Methods}

After the initial assessment, participants attended a training on cooking activities and, together with the therapist, they learned how to make simple dishes. The therapist provided guidance and assisted participants as they learned safe ways to cook. Both the cooking test and the training were performed in a large kitchen that was set up for disabled users (see Figure 1). This kitchen was equipped with many utensils: non-slip carpets, adapted chopping boards, and ergonomic glasses.

The training consisted of 10 twice weekly sessions, each one lasting $90 \mathrm{mi}-$ nutes. During each session all participants had to perform a series of tasks, including: read the recipe, prepare materials and ingredients and then complete the food preparation. The difficulty of the tasks gradually increased, such that at the beginning activities were simple to allow the patients to familiarize themselves with the setting but later, recipes were chosen by the patients themselves, with the supervision of the therapist.

The training had motor and neuropsychological objectives. It aimed to improve dexterity, manipulation, bi-manual coordination/integration, as well as static and dynamic equilibrium. Neuropsychological objectives included the improvement of procedural and task planning abilities, organization, problem-solving, attention and memory skills. It aimed also to increase the awareness of the limitations due to the disease, and to promote the use of some devices for greater safety and independence.

During each session, the therapist could give suggestions regarding posture, advices for dexterity, and warnings on the use of tools. At the end of each session, each patient received homework in order to remind them of the procedures that were learned in each session.

\section{Results}

Considering the UPDRS score, both at the beginning and at the end of training, the greater disability was perceived on ADL and motor aspects. At the end of the training, the global mean score reduced from 9.8 to 7.9 , indicating an improvement in perceived disability. This change was mainly due to a reduction of scores on ADL and motor subscales (see Figure 2).

Results concerning the Parkinson's Disease Quality of Life questionnaire are reported in Table 1. Participants reported mainly difficulties on motor functioning, as tremor, rigidity and slowing down of movements that impaired on daily living activities.

The mean rating on the $S c h w a b$ \& England Scale increased from a mean of $77.5 \%(\mathrm{sd}=15.58)$ to a mean of $80 \%(\mathrm{sd}=14.14)$, indicating an increase in perceived independence. The mean score on FIM was $108(\mathrm{sd}=13.55)$ both at the beginning and at the end of the training. The performance in cooking test improved, 


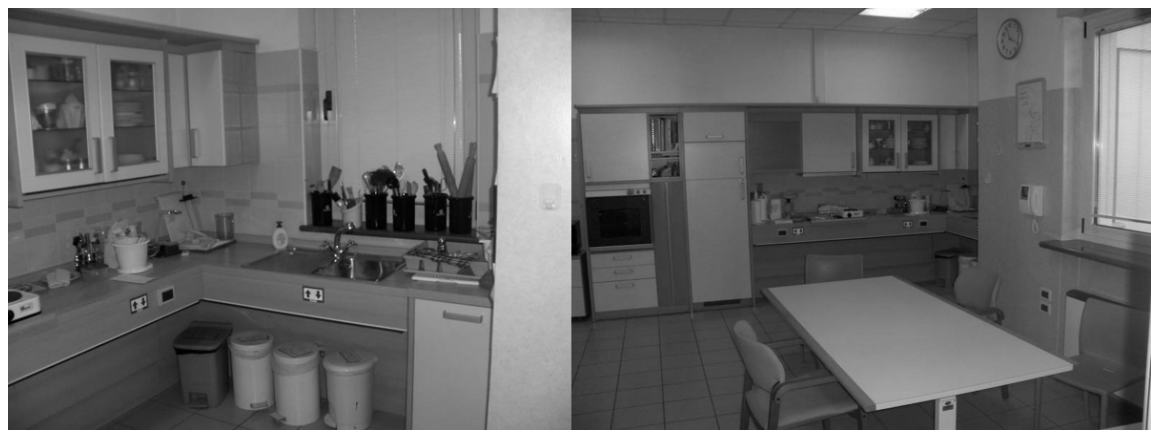

Figure 1. Pictures of the kitchen where the cooking training took place.

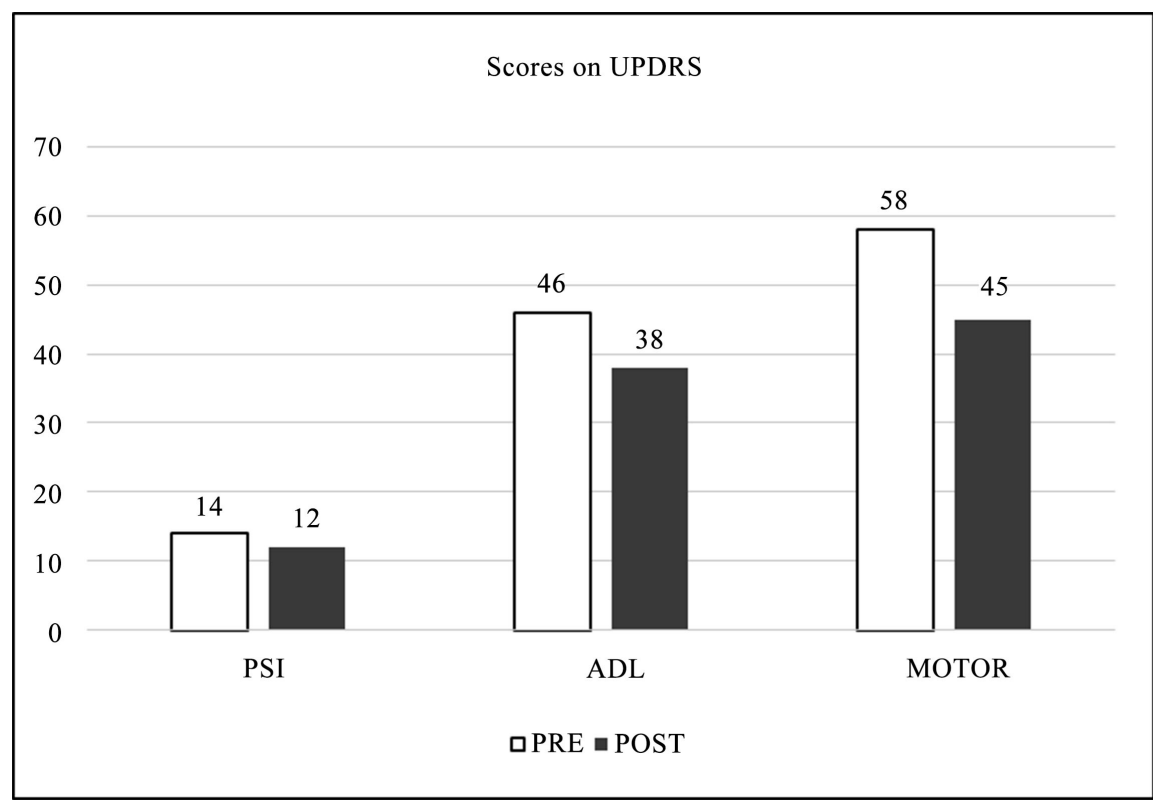

Figure 2. Mean score of UPDRS subscales at the beginning (white bars) and at the end (black bars) of occupational training. 199 represents total disability whereas 0 represents no disability.

Table 1. Difficulties reported in the Parkinson's Disease Quality of Life at the beginning and at the end of the occupational training.

\begin{tabular}{|c|c|c|}
\hline \multicolumn{3}{|c|}{$\underline{\text { Parkinson's Disease Quality of Life }}$} \\
\hline Patient & $\underline{\text { Pre }}$ & $\underline{\text { Post }}$ \\
\hline 1 & Being tense & $\begin{array}{c}\text { Being tense } \\
\text { Difficulties writing }\end{array}$ \\
\hline 2 & Being tense & $\begin{array}{l}\text { Difficulties turning around while walking } \\
\text { Reduction in falls }\end{array}$ \\
\hline 3 & $\begin{array}{l}\text { Difficulties getting up (from a chair) } \\
\text { Difficulty with sitting still (for long periods) } \\
\text { Difficulties turning around in bed }\end{array}$ & Difficulties getting up (from a chair) \\
\hline 4 & $\begin{array}{l}\text { Feeling worn out or having no energy } \\
\text { Difficulties getting up (from a chair) } \\
\text { Difficulties turning around in bed }\end{array}$ & Difficulties turning around in bed \\
\hline
\end{tabular}


both in observed quality and in speed of performance (see Table 2).

Patient 1 improved her motor performance: her gestures became smoother and her dexterity generally improved. In the first assessment she was unable to knead, whereas during the final one she kneaded and cut up the mozzarella without difficulty. Her posture, although uncertain and rather slow, was maintained with greater confidence. Following the therapist's suggestions, she learned to use her stick or to hold onto the cupboards. She also acquired strategies to improve her ability to move and manage the ingredients.

Patient 2 improved her ability to plan and organize the task. At the beginning, she carried out the activities in a clumsy, hurried and disorganized way. At the end of the training, she was able to follow the recipe, orderly and effectively.

Patient 3 acquired personal organizational strategies, for example she learned to suspend the work before becoming too tired, to sit down to cut, to slice, and to wash up.

Patient 4 learned and adopted memory strategies in order to remember the sequences within the task. She became less hesitant and more confident in the kitchen. No significant modifications occurred on tremors and rigidity.

The questionnaire for satisfaction showed a positive evaluation, the training on cooking was considered a stimulating experience. Patients perceived an increased in self-efficacy, felt more comfortable with other patients and with the therapist. They recovered their passion for cooking activities and also for other activities related to daily living. All caregivers reported a greater involvement of the patient in the management of the $\mathrm{ADL}$ and a reduction in care required. They also stated that the treatment was useful for increasing clients' awareness. This improvement in awareness helped patients choose and be committed to doing activities suitable for them.

Table 2. Speed (in minutes) and quality of performance in the practical functional test for each patient at the beginning and at the end of the occupational training.

\begin{tabular}{|c|c|c|}
\hline \multicolumn{3}{|c|}{$\underline{\text { Practical functional test }}$} \\
\hline Patient & $\underline{\text { Pre }}$ & $\underline{\text { Post }}$ \\
\hline 1 & $\begin{array}{l}\text { Time: } 50 \text { ' } \\
\text { Unable to knead. Constant rigidity. Slow } \\
\text { unstable movements. }\end{array}$ & $\begin{array}{l}\text { Time: } 45^{\prime} \\
\text { More able to knead. }\end{array}$ \\
\hline 2 & $\begin{array}{l}\text { Time: } 35 \text { ' } \\
\text { Rigidity and instability when changing } \\
\text { position. Hurried during the performance. }\end{array}$ & $\begin{array}{l}\text { Time: } 20 \text { ' } \\
\text { More precise when performing the task. }\end{array}$ \\
\hline 3 & $\begin{array}{l}\text { Time: } 20 \\
\text { Slightly slow movements. Good dexterity. }\end{array}$ & $\begin{array}{l}\text { Time: } 15^{\prime} \\
\text { Good dexterity }\end{array}$ \\
\hline 4 & $\begin{array}{l}\text { Time: } 20 \text { ' } \\
\text { Moderately slow to carry out the task. } \\
\text { Slight rigidity. }\end{array}$ & $\begin{array}{l}\text { Time: } 15 \\
\text { Moderately slow in performing the task. } \\
\text { More satisfied with the result. }\end{array}$ \\
\hline
\end{tabular}




\section{Discussion}

The aim of this study was to explore the effects of a training on cooking with 4 women affected by Parkinson's Disease. The training led to improvement on activities of daily living and on movements, as measured by the UPDRS and as was observed in the cooking test. This was related to an increased perceived independence: for most of patients, the perceived level of difficulty in daily life was reduced; participants felt more self-confident concerning their abilities and improved their awareness about the consequences of disease. These benefits may improve the self-efficacy and the ability of patients to care for themselves (Suchowersky et al, 2006). With the exception of Patient 1, other participants started again to cook; their caregivers observed an increase in participation and a subsequent reduction of the burden in the management of the activities of daily living. Beyond these improvements, group training stimulated participation and promoted also proactive coping skills with benefit on overall quality of life.

\section{Conclusions}

This paper presents results of a training on cooking for women with Parkinson's disease. Parkinson's disease is a chronic progressive disease of the central nervous system characterized by tremor, bradykinesia, rigidity and postural instability as cardinal features (Choi et al., 2017). As consequence of these impairments, it results in a progressive decline in functional activities and independent daily living (Kim et al., 2011). For these reasons, the level of participation in activity of daily living should be a primary outcome in intervention studies and training to support and maintain patients' abilities should be part of the rehabilitative program. Results of this preliminary study suggest that a training on cooking improves the course of the Parkinson's disease: it supports the quality of general movements as well as psychological aspects as mood, awareness and social relationships.

Our findings suggest that an occupational training on cooking should be part of the management of the Parkinson's disease. Future research should include more participants and should examine longer term effects of the intervention both on patients and their caregivers' quality of life.

\section{Conflicts of Interest}

The authors report no conflicts of interest. The authors alone are responsible for the content and writing of the paper.

\section{References}

Center for Functional Assessment Research (2006). Uniform Data System for Medical Rehabilitation UDSmr, Buffalo NY, USA Functional Indipendence Measure Italian Version: Strumento di misura della disabilità. Istituto Auxologico Italiano.

Choi, Y. I., Song, C. S., \& Chun, B. Y. (2017). Activities of Daily Living and Manual Hand Dexterity in Persons with Idiopathic Parkinson Disease. Journal of Physical Therapy 
Science, 29, 457-460. https://doi.org/10.1589/jpts.29.457

Cholewa, J., Gorzkowska, A., Szepelawy, M., Nawrocka, A., \& Cholewa, J. (2014). Influence of Functional Movement Rehabilitation on Quality of Life in People with Parkinson's Disease. Journal of Physical Therapy Science, 26, 1329-1331. https://doi.org/10.1589/jpts.26.1329

Fahn, S., \& Elton, R. L. (1987). UPDRS Program Members. Unified Parkinsons Disease Rating Scale. In: S. Fahn, C. D. Marsden, M. Goldstein, \& D. B. Calne (Eds.), Recent Developments in Parkinsons Disease (Vol. 2, pp. 153-163). Florham Park, NJ: Macmillan Healthcare Information.

Hartmann, E. (2000). Parkinson e l'approccio riabilitativo multidisciplinare. Speciale riabilitazione (Eds). Milano.

Hobson, P., Golden, A., \& Meara, J. (1999). Measuring the Impact of Parkinson's Disease with the Parkinson's Disease Quality of Life Questionnaire. British Geriatrics Society, 28, 341-346. https://doi.org/10.1093/ageing/28.4.341

Hoehn, M. M., \& Yahr, M. D. (1967). Parkinsonism: Onset, Progression and Mortality. Neurology, 17, 427-442. https://doi.org/10.1212/WNL.17.5.427

Kim, H. D., Kim, T. Y., Jae, H. D., \& Son, S. T. (2011). The Effects of Tai Chi Based Exercise on Dynamic Postural Control of Parkinson's Disease. Journal of Physical Therapy Science, 23, 265-269. https://doi.org/10.1589/jpts.23.265

Macleod, A. D., Grieve, J. W., \& Counsell, C. E. (2016). A Systematic Review of Loss of Independence in Parkinson's Disease. Journal of Neurology, 263, 1-10.

https://doi.org/10.1007/s00415-015-7847-8

Pezzoli, G., \& Tesei, S. (2015). Guida alla Malattia di Parkinson, Associazione Italiana Parkinsoniani (Eds). Milano.

Schwab, R. S., \& England, A. C. (1969). Projection Technique for Evaluating Surgery in Parkinson's Disease ed. Third Symposium on Parkinsons Disease. Edinburgh: E.S. Livingston

Suchowersky, O., Reich, S., Perlmutter, J., Zesiewicz, T., Gronseth, G., Weiner, W. J. et al. (2006). Practice Parameter: Diagnosis and Prognosis of New Onset Parkinson Disease (An Evidence-Based Review): Report of the Quality Standards Subcommittee of the American Academy of Neurology. Neurology, 66, 968-975. https://doi.org/10.1212/01.wnl.0000215437.80053.d0

Tombaugh, T. N., \& McIntyre, N. J. (1992). The Mini-Mental State Examination: A Comprehensive Review. Journal of the American Geriatric Society, 40, 922-935. https://doi.org/10.1111/j.1532-5415.1992.tb01992.x

World Health Organization (1948). Costitution of the World Health Organization. Basic Documents, Geneva: WHO.

World Health Organization (2001). International Classification of Functioning, Disability, and Health (ICF). Geneva: WHO. 